\title{
Aspiração por reconhecimento e educação do amor-próprio em Jean-Jacques Rousseau*
}

\author{
Claudio Almir Dalbosco \\ Universidade de Passo Fundo
}

Para Hans-Georg Flickinger ${ }^{\star *}$

Correspondência:

Claudio Almir Dalbosco

Rua Independência 1006/81

99010-04 - Passo Fundo (RS)

E-mail: vcdalbosco@hotmail.com

* Trabalho vinculado ao projeto de pesquisa "lluminismo e Pedagogia: educação natural e formação humana no Émile de Rousseau", financiado pelo CNPq na modalidade de Bolsa Produtividade em Pesquisa.

** Agradeço ao Hans-Georg Flickinger pelas inúmeras críticas e sugestões. Além disso, devo ao privilégio de sua parceria intelectual crítica meu interesse por filosofia social e sua indispensabilidade à reflexão sobre problemas pedagógicos.

\section{Resumo}

0 artigo procura mostrar a existência de uma filosofia social no Segundo discurso de Rousseau, tomando a aspiração humana por reconhecimento como seu núcleo constitutivo. A investigação sobre a origem da desigualdade conduz o genebrino à interrogação acerca do próprio homem, descobrindo a liberdade e a perfectibilidade como forças (faculdades) originárias de sua sociabilidade. Pela liberdade o homem chega à consciência de sua espiritualidade, ou seja, torna-se apto a ir além do mecanicismo causal imposto pela natureza, construindo o universo linguístico, simbólico e cultural. Pela perfectibilidade, o homem adquire a capacidade de tornar-se cada vez melhor e apto não só para lutar pela sua sobrevivência imediata, como também para aspirar ser reconhecido pelos demais. Em sintese, liberdade e perfectibilidade abrem-lhe as portas para a sociabilidade e permitem-lhe ingressar no universo cultural. Contudo, simultâneo ao processo de tornar-se um ser livre e capaz de se aperfeiçoar, o homem desenvolve a capacidade de sair fora de si mesmo, sentindo a necessidade da comparação permanente com os demais. Isso marca, do ponto de vista da constituição humana, a passagem do amor de si para o amor-próprio: enquanto o primeiro é representativo do estado natural e está baseado na piedade, o segundo caracteriza o homem civil e está marcado pela propensão do homem de querer ocupar uma posição superior em relação aos demais. Se tal propensão se tornar incontrolável, ela pode conduzir à destruição da sociabilidade. Daí a necessidade de sua regulação jurídica e política, acompanhada, previamente, por um processo de formação pedagógica e moral. Isso justifica então a necessidade de educação permanente do amor-próprio.

\section{Palavras-chave}

Reconhecimento - Educação - Amor-próprio - Educação natural. 


\title{
Aspiration for recognition and the education of self-love in Jean-Jacques Rousseau*
}

\author{
Claudio Almir Dalbosco \\ University of Passo Fundo
}

To Hans-Georg Flickinger ${ }^{\star *}$

\footnotetext{
Contact:

Claudio Almir Dalbosco

Rua Independência 1006/81

99010-04 - Passo Fundo (RS)

E-mail: vcdalbosco@hotmail.com

* This work is associated to the research project "Enlightenment and Pedagogy: natural education and human formation in Rousseau's Émile, sponsored by CNPq with a Research Productivity Scholarship.

** I wish to thank Hans-Georg Flickinger for his innumerable criticisms and suggestions. Also, I owe to the privilege of having his intellectual companionship my own interest for social philosophy and for its indispensability in the reflection about pedagogical problems.
}

\begin{abstract}
The article seeks to demonstrate the existence of a social philosophy in Rousseau's Second discourse, which takes the human aspiration for recognition as its constitutive core. The investigation on the origin of inequality leads the Genevan to his questionings about men himself, discovering freedom and perfectibility as originary strengths (faculties) of his sociability. Through freedom man arrives at the awareness of his spirituality, that is, becomes capable of going beyond the causal mechanicism imposed by nature, constructing the linguistic, symbolic and cultural universe. Through perfectibility man acquires the ability to become better and better, and ready not only to fight for his immediate survival, but to aspire to be recognized by the others. In summary, freedom and perfectibility open to him the doors to sociability, and allow him to enter the cultural universe. However, concomitantly to the process of becoming a free being, capable of perfecting itself, man develops the ability to step outside himself, feeling the need for constant comparison with the others. That heralds, from the point of view of the human constitution, the passage from the love of oneself (amour de soi) to self-love (amour-propre): whilst the former is representative of the natural state and is based on piety, the latter characterizes the civilized man, and is marked by man's propensity to wish to occupy a higher position than the rest. If such propensity is not curtailed, it can lead to the destruction of sociability. Hence the need for its juridical and political regulation, anteceded by a process of moral and pedagogical formation. This then justifies the need for the permanent education of self-love.
\end{abstract}

\section{Keywords}

Recognition - Education - Self-love - Natural education. 


\section{Introdução}

Quando decide concorrer ao prêmio da Academia de Dijon, Rousseau vê-se confrontado com a tarefa de ter que responder à pergunta pela origem da desigualdade entre os homens. Sua resposta não é de modo algum simples nem direta, pois, ao meditar sobre o problema, é conduzido à conclusão de que uma explicação adequada à questão só pode ser alcançada mediante a investigação acerca da natureza humana. Amparando-me na interpretação de Neuhouser (2009), pretendo mostrar, neste ensaio, que a resposta formulada por Rousseau contém o esboço de uma filosofia social do reconhecimento humano baseada no conceito de amor-próprio.

Em sintese, defenderei a tese de que, para dar conta da investigação sobre os fundamentos da sociabilidade humana, Rousseau desenvolve uma teoria do reconhecimento humano, pondo em sua base o conceito de amor-próprio. Penso que a legitimação de tal tese pressupõe um tratamento adequado, pelo menos, da seguinte questão: em que sentido a aspiração humana por reconhecimento exige a capacidade do sujeito de sair fora de si e, comparando-se permanentemente com os outros, desenvolver a capacidade de assumir sua perspectiva? Buscar uma resposta para esta pergunta com base, primeiro, na reconstrução de algumas passagens do Segundo discurso ${ }^{1}$ e, depois, na análise da posição de Neuhouser, é o objetivo principal deste ensaio.

\section{A constituição do laço social no Segundo discurso: o problema da} necessidade de comparação com o outro

Em 1753, a Academia de Dijon apresenta a questão "Qual a origem da desigualdade entre os homens e será ela permitida pela lei natural?", com o propósito de orientar o trabalho dos interessados pelo prêmio que seria oferecido ao ganhador no ano seguinte.

1. Abreviatura usual da obra Discours sur l'origine et les fondemens de l'inégalité parmi les hommes.
Rousseau decide concorrer e escreve o Segundo discurso. A resposta dada à pergunta não é de modo algum simples nem direta, pois implica o movimento complexo de pensamento que delineia os traços gerais de uma filosofia social baseada no fato antropológico da incessante aspiração humana por reconhecimento social.

0 leitor familiarizado com a filosofia social desenvolvida a partir de Hegel e que desemboca, no século XX, na ampla tradição da teoria crítica da sociedade, logo percebe, no argumento de Rousseau, a vinculação estreita entre os traços de sua teoria da sociedade e uma antropologia de origem eminentemente filosófica. Nesse sentido, o genebrino pensa que a resposta satisfatória à pergunta pela origem da desigualdade entre os homens deve conduzir à investigação acerca dos fundamentos da sociabilidade humana, a qual, por sua vez, remete à pergunta mais fundamental de quem é o próprio homem.

A reflexão acerca do nexo estreito entre sociabilidade e natureza humana sustenta-se na dupla capacidade humana, da exteriorização e da comparação, tornada possível, por sua vez, pela dupla condição humana, da liberdade e da perfectibilidade. Isto é, porque se tornou progressivamente um agente livre e capaz de se aperfeiçoar é que o ser humano adquiriu a capacidade de sair fora de si mesmo e, com isso, viu-se permanentemente inclinado a comparar-se com os outros. Contudo, esta complexa dinâmica da aspiração humana para se comparar incessantemente com os outros, a qual se encontra exposta por Rousseau em algumas passagens do Segundo discurso, deve ser objeto de uma análise mais cuidadosa, uma vez que tal dinâmica é decisiva para a compreensão da ambiguidade constitutiva do amor-próprio e da necessidade de sua educação.

A justificativa da filosofia do reconhecimento social baseada numa antropologia de matriz filosófica segue a estruturação geral, dividida em duas partes, do Segundo discurso. $\mathrm{Na}$ primeira, Rousseau expõe o homem primitivo e o homem natural, assinalando a liberdade e 
a perfectibilidade como "faculdades" ou forças impulsionadoras do nascimento do homem civil. A ideia tanto de homem selvagem como de homem natural é um construto adotado para fugir do círculo entre estado de natureza e sociedade, no qual incorriam facilmente, segundo ele, os defensores do direito natural de sua época e, com isso, poder oferecer uma explicação satisfatória para o corrompido estado social atual. Na segunda parte, são descritos os estágios e as características iniciais da sociedade, mostrando o desenvolvimento da metalurgia, da agricultura e o nascimento da propriedade e do corpo político, este último legitimado pelo contrato entre povo e governante. Com a exposição destas duas partes, Rousseau chega à conclusão de que

[...] sendo quase nula a desigualdade no estado de natureza, deve sua força e seu desenvolvimento a nossas faculdades e aos progressos do espírito humano, tornando-se, afınal, estável e legítima graças ao estabelecimento da propriedade e das leis. (OC III $195 ; 1978$, p. 282) ${ }^{2}$

A reconstrução do núcleo constitutivo da filosofia do reconhecimento social dispensa-me agora de tratar diretamente das dificuldades inerentes ao procedimento metodológico adotado por Rousseau e também de sua exposição do homem selvagem, do homem natural e do homem civil. 0 que importa, sim, ao meu ponto, é a reconstrução daquilo que cimenta o laço social e que, portanto, está na base da sociabilidade humana.

Com isso fica estabelecido que o estudo da constituição do laço social conduz à investigação sobre a constituição do laço propriamente humano, ou seja, daquilo que forma a natureza do homem. Mas por que afinal - poderíamos ainda nos perguntar - a antropologia

2. Todas as citações da obra de Rousseau serão feitas como a que seguiu, indicando-se primeiro a obra no original, abreviada como $\mathrm{OC}$, seguida do volume em romano e da paginação em arábico; por fim, 0 ano e a paginação da tradução portuguesa empregada. filosófica deve sustentar a explicação sobre a origem e constituição da sociabilidade humana e, mais precisamente, de um tipo determinado de sociabilidade? Enfım, por que a investigação sobre quem é o homem deve ser tomada como condição de possibilidade da compreensão daquele homem que vive socialmente de modo inautêntico e corrompido?

Para tratar destas questões precisamos acompanhar o movimento teórico de Rousseau, o qual inicia com o regresso hipotético para uma situação imaginária na qual o "homem teria saído das mãos da natureza" e, a partir daí, o genebrino acompanha o processo evolutivo que teria marcado, progressivamente, o surgimento do homem civil: do estado selvagem passa para o estado natural e deste para o estado civil. Como o percurso de pensamento é hipotético, não interessa tanto "nem os livros científicos" e nem as "verdades históricas”, mas sim a meditação sobre o que teriam sido supostamente as primeiras e mais simples operações da alma humana. Ora, a meditação sobre esta simplicidade original revela dois princípios constitutivos do homem selvagem, a saber, a autoconservação, sustentada pelo amor de si e a piedade, a qual é a fonte natural do compadecimento humano pelo sofrimento do outro.

0 aspecto determinante desta longa evolução é a capacidade eminentemente humana de comparar-se com os outros que tem seu início ainda com o próprio homem selvagem. 0 primeiro ato originário de comparação dá-se não diretamente entre os próprios homens, mas sim entre eles e os outros animais. Assim afirma Rousseau:

Mas o homem selvagem, vivendo disperso entre os animais e vendo-se desde cedo na iminência de medir forças com eles, logo fez a comparação (comparaison) e, verificando que mais os ultrapassa em habilidade do que eles o sobrepujam pela força, aprende a não mais temê-los. (OC III 136; 1978, p. 239) 
De acordo com a passagem citada, o primeiro confronto decisivo que está na origem da sociabilidade humana é marcado pela habilidade humana rudimentar versus a força física superior de outros animais. Com isso, o contato inicial do homem com outros animais, movido pela necessidade de conservação, coloca-o na condição de observador natural e o conduz à percepção detida sobre sua posição de superioridade. Ao perceber que é superior, não em força, mas em habilidade, o homem perde progressivamente o medo dos outros animais e enfrenta-os na luta pela sua autoconservação. Portanto, a condição de observador, ainda que muito rudimentar em seu início, coloca o homem na posição superior em relação mesmo àqueles animais que pela força física lhe são infinitamente superiores.

No Segundo discurso aparece, portanto, como podemos observar, o tema da autoconservação e da sociabilidade humana. Como o tema da conservatio sui, embora presente na tradição filosófica antiga e medieval, torna-se central à modernidade filosófica, cabe referir aqui, ainda que brevemente, duas posições de um debate ocorrido nos anos setenta do século passado na Alemanha, que foi magistralmente documentado por Hans Ebeling (1996).

A primeira posição é de Dieter Henrich (1996), o qual mostrou como a teoria moderna da subjetividade depende de um conceito de sujeito que tem sua âncora no princípio de autoconservação. Tal princípio estende-se para além da significação biológica ou psicológica, assumindo o sentido de um princípio racional (filosófico). Como princípio filosófico moderno, a autoconservação não consiste, como a pensou Aristóteles, na tranquilidade do gozo de um fim alcançado, mas sim na alegria do resultado contínuo de alcançar todas as coisas desejadas. Neste sentido, a vida é movimento, mas não do gozo de um fim alcançado, senão de fim para fim. Ora, esta "estrutura antropológica" da autoconservação se mostra também na vontade unida dos cidadãos no Estado e, neste sentido, a conservatio sui é o princípio racional tanto da vida individual como da vida social (HENRICH, 1996, p. 98-99). Na sequência de sua argumentação, Henrich procura mostrar como a autoconservação identifica-se, na modernidade, com a autoconsciência.

A segunda posição é a de Günther Buck, a qual está mais diretamente relacionada ao nosso tema. Rousseau procura se distanciar, segundo Buck, do pensamento teleológico antigo e tal esforço leva-o à descoberta da historicidade, cujo centro repousa na ideia da autoconservação. Neste sentido, o genebrino pensa a conservatio sui a partir do ideal da autonomia como historicidade, pois o princípio do "être soi-même" só pode ser descoberto como princípio a partir da experiência histórica do autoestranhamento. $\mathrm{Ou}$ seja, tal princípio surge da exegese que o sujeito faz de sua própria experiência e situação histórica (BUCK, 1996, p. 219).

Esta breve referência à posição de Henrich e Buck avaliza a conclusão de que a autoconservação, no sentido filosófico moderno, se distancia do simples instinto de luta pela sobrevivência, transformando-se no princípio racional de organização da vida individual e social. No entanto, como nos mostra o Segundo discurso, tal princípio tem uma gênese que começa a se desenvolver efetivamente quando se vincula à liberdade e à perfectibilidade.

Retomemos, novamente, o fio condutor da exposição: a dupla condição da liberdade e da perfectibilidade empurra o homem para fora de si mesmo, brotando deste movimento o desejo de comparação com os outros e a aspiração incessante por reconhecimento. Há nesta complexa dinâmica o surgimento de um componente decisivo, sem o qual, segundo Rousseau, não se poderia compreender o fenômeno da sociabilidade: trata-se do surgimento do sentimento do amor-próprio. 0 aparecimento progressivo do amor-próprio tira o homem selvagem de seu isolamento e 
o empurra cada vez mais para a sociabilidade ${ }^{3}$. Com isso, a capacidade de comparação de sua relação direta com os animais passa para sua relação com seus próprios semelhantes, e, nesta nova situação, a comparação assume uma dinâmica inteiramente própria.

Rousseau descreve magnificamente, na segunda parte do Segundo discurso, o momento em que os homens deixam de viver isolados nos bosques e se aproximam lentamente, formando em cada região "uma nação particular, una de costumes e caracteres" (OC III 169; 1978, p. 263). Esta aproximação lenta conduz para o intercâmbio social, pois, na medida em que as famílias se aproximam territorialmente, facilitam o contato pessoal, permitindo que "jovens de sexo diferente habitem cabanas vizinhas" (OC III 169; 1978, p. 263). Ocorre aí, neste momento, a passagem daquela situação em que os homens primitivos vagavam isoladamente nos bosques, buscando sua sobrevivência, para o estado no qual eles começam a se aglutinar em famílias, fixando residência. Temos, então, a condição elementar exigida para um intercâmbio social mínimo.

Mas temos dadas também, sob estas circunstâncias, as condições para o surgimento da comparação social. No contexto de sua reflexão sobre o homem selvagem, afırma Rousseau:

Acostumam-se a considerar os vários objetos e a fazer comparações (comparaison): insensivelmente adquirem-se idéias de mérito e de beleza, que produzem sentimentos de preferência. À força de se verem, não pode mais deixar de novamente se verem. Insinua-se na alma um sentimento terno e doce, e, à menor oposição, nasce um furor impetuoso (fureur impétuese); com o amor surge o ciúme, a discórdia triunfa e a mais doce paixão recebe sacrifícios de sangue humano. (OC III 169; 1978, p. 263)

3. Para evitar que o surgimento do amor-próprio seja interpretado como um "súbito" aparecimento, é preciso considerar que Rousseau o concebe estritamente ligado tanto à liberdade como à perfectibilidade, e a sociabilidade só é possível pela ação destas duas forças ("faculdades humanas").
A passagem citada contém a ideia de que, ao se compararem entre si, os homens tornam-se insensíveis, adquirindo sentimentos de preferência que os levam a escolher esta ou aquela companhia, este ou aquele parceiro, em detrimento de outros. Mais ainda, uma vez estabelecido o vinculo e aprendido a viver em companhia, os homens não conseguem mais viver isolados, preferindo mesmo suportar duramente o sofrimento e as dores que a convivência lhes causa do que terem que voltar a viver de novo isoladamente. Por fim, é digno de nota o quanto a sociabilidade emergente já é responsável por causar o misto de sentimento que arrebatará definitivamente o homem civil, obrigando-o a viver tensionalmente orientado ora pela docilidade, ora pelo ímpeto agressivo. Deste modo, segundo a passagem, já em sua origem, o amor humano encontra-se carregado tanto pelo "sentimento terno" como pelo "furor impetuoso", indicando-se, com isso, que a sociabilidade humana não poderia mais ser orientada tão somente pela "voz doce" do homem selvagem.

No suceder de ideias e sentimentos, o gênero humano foi se domesticando, ampliando suas ligações e apertando seus laços. Neste contexto de convivência mais intensa, aumenta também o desejo de comparação, fazendo com que cada um olhe e observe permanentemente o outro. É desta dinâmica do olhar permanente para os outros e do querer ser também por eles olhado que nasce l'estime publique. Assim, afirma Rousseau:

Aquele que cantava ou dançava melhor, o mais belo, o mais forte, o mais astuto ou o mais eloqüente, passou a ser o mais considerado [...]; dessas primeiras preferências nasceram, de um lado, a vaidade e o desprezo, e, de outro, a vergonha e a inveja. (OC III 169; 1978, p. 263)

Parece ficar claro, com isso, que essas “primeiras preferências” já engendram a aspiração humana por reconhecimento e, uma vez 
que é resultado do procedimento que mais destaca um sujeito em relação aos outros, tal reconhecimento gera, inevitavelmente, sentimentos de vaidade e inveja.

Compreendendo-se enquanto comportamento baseado no olhar e no deixar-se olhar permanentemente, a comparação contém em si, portanto, uma dinâmica interna que possibilita o ser humano ser tomado em condição de superioridade em relação aos outros. Tal dinâmica impede que todos sejam reconhecidos simultaneamente e na mesma proporção. Ora, isso conduz a uma tensão que marca a busca por estima pública (por reconhecimento social) e, como ainda veremos adiante, quando se consolida como conduta do homem civil, empurra-o para o mundo do parecer e da artificialidade. Nesse contexto, Rousseau põe o núcleo de sua filosofia social nos seguintes termos: "Para proveito próprio, foi preciso mostrar-se diferente do que na realidade se era. Ser e parecer tornam-se duas coisas totalmente diferentes" (OC III 174; 1978, p. 267).

Pela socialização o homem forma no espírito a "idéia de consideração, [sendo que] cada um pretendeu ter direito a ela e a ninguém foi mais possível deixá-la de tê-la impunemente" (OC III 169; 1978, p. 263). De tal ideia brotaram os primeiros deveres de civilidade, e toda a afronta voluntária passou a ser considerada como ultraje, uma vez que provocava no ofendido um sentimento de desprezo por sua própria pessoa. A consciência do desprezo por sua própria pessoa torna-se, desse modo, um peso insuportável, difícil de ser carregado.

Em outra passagem, Rousseau enfatiza a lógica da sociabilidade humana baseada na busca desenfreada pela distinção considerando tal comportamento como causa de “nossas virtudes e de nossos vícios". Assim, afirma ele: "Mostraria que é a tal ânsia de fazer falar de si, a esse furor de distinguir-nos, quase sempre nos colocando fora de nós, que devemos o que há de melhor e de pior entre os homens" (OC III 189; 1978, p. 278). Mas é numa outra passagem, já quase no fim do
Segundo discurso, que encontramos formulado, lapidarmente, o argumento nuclear da sociabilidade humana:

Tal, com efeito, a verdadeira causa de todas essas diferenças: o selvagem vive em si mesmo; o homem sociável (l'homme sociable), sempre fora de si, só sabe viver baseando-se na opinião dos demais e chega ao sentimento de sua própria existência quase que somente pelo julgamento destes. (OC III 193; 1978, p. 281)

Ou seja, a opinião e o olhar do outro tornam-se o aspecto constitutivo da sociabilidade humana. Uma vez tocado pelo olhar do outro, o homem não consegue mais viver em si mesmo e, com isso, precisa buscar no outro as motivações para a constituição de si mesmo. Fica assinalado também, com isso, como característica central do homem sociável, que ele só consegue adquirir o "sentimento de sua existência” com base na estima pública, ou seja, com base no julgamento frequente que recebe do outro.

Em síntese, na busca por resposta à pergunta colocada pela Academia de Dijon, Rousseau é levado a ver na capacidade humana de sair fora de si mesmo e na necessidade do homem de se comparar permanentemente com os outros, visando ser melhor do que eles, a origem da dinâmica que marca o início e o aprofundamento da sociabilidade humana. Com o ingresso do amor-próprio em cena, tal sociabilidade ganha direção e contornos bem específicos.

\section{Do caráter ambíguo do amor-próprio}

Procurei alinhavar acima, em largos traços, o que poderia ser tomado, no Segundo discurso, como argumento principal a favor de uma filosofia social baseada na aspiração humana por reconhecimento. No entanto, tal filosofia ficaria muito incompleta sem o recurso 
ao conceito do amor-próprio; talvez pudéssemos dizer que sem tal recurso ela não teria sido nem mesmo possivel. 0 problema é que, dado o status que ocupa no pensamento de Rousseau, tal conceito não recebeu dele a consistência e o esclarecimento merecidos. Para agravar ainda mais a situação, também não impera consenso entre seus intérpretes, destacando-se duas posições bem antagônicas: de um lado, há a posição standard, que sustenta apenas o caráter destrutivo do amor-próprio; de outro, a posição que ressalta seu caráter ambíguo, extraindo disso a possibilidade de educação do amor-próprio. 0 exemplo da primeira encontra-se no estudo de Fetscher (1975); da segunda, na interpretação de Neuhouser (2009).

Como já tratei criticamente da primeira posição em outro ensaio (DALBOSCO, 2009, p. 13-33), gostaria de me ocupar agora, especificamente, com a posição de Neuhouser (2009), reconstruindo apenas os traços gerais de sua interpretação que interessam ao ponto em discussão. Desse modo, busco na posição de Neuhouser um argumento adicional forte a favor do papel constitutivo do amor-próprio em relação à sociabilidade moral baseada no respeito social mútuo e no reconhecimento ético do outro. Além disso, a reconstrução de aspectos pontuais de sua posição auxilia-me a ver que argumentos são favoráveis à tese da existência de uma filosofia social no pensamento de Rousseau. Por fim, o recurso à sua interpretação contribui também à justificativa sobre a importância da educação do amor-próprio.

Neuhouser parte da tese de que Rousseau sustenta sua filosofia do reconhecimento social no conceito do amor-próprio; ou seja, esta tese quer dizer, segundo ele, que a aspiração humana por reconhecimento está baseada no sentimento do amor-próprio. Para investigar esse conceito, o autor empreende um duplo movimento em sua interpretação, concebendo-o, por um lado, como fonte do mal e, por outro, como antídoto contra a maldade da qual ele próprio é culpado. Como não posso me ater aqui na riqueza de detalhes proporcionada por sua interpretação, devo resumir tão somente os aspectos centrais que caracterizam a ambiguidade do amor-próprio.

Primeiro, no que diz respeito à tese de que o amor-próprio é a fonte do mal. Para reconstruir essa dimensão negativa e destrutiva do amor-próprio, Neuhouser (2009, p. 28-29) busca defini-lo em oposição ao sentimento do amor de si. Parte da consideração geral de que o amor de si e o amor-próprio são duas formas do amor por si mesmo que põem em jogo o sentido autêntico do ser humano. Ou seja, segundo ele, Rousseau pensou que a constituição do si mesmo humano estava profundamente vinculada com o amplo sentimento de amor que cada indivíduo possui por si mesmo. Este sentimento de amor por si mesmo adquire, por sua vez, uma dupla dimensão, desdobrando-se no sentimento natural originário do amor de si (amour-de-soi) e no sentimento eminentemente social do amor-próprio (amour-propre).

A primeira oposição nítida entre esses dois sentimentos se refere ao fato de que um diz respeito à conservação física do homem e o outro à sua sociabilidade. Enquanto o amor de si está diretamente relacionado com a autoconservação humana e é representativo do homem selvagem e natural, o amor-próprio define a dinâmica da sociabilidade humana, sendo, por isso, constitutivo do homem civil e de suas produções culturais e institucionais. Como constitutivo da sociabilidade, o amor-próprio está a serviço, desde o instante de seu surgimento, da honra e do mérito, relacionando-se com o problema de como o indivíduo pode ser bem visto. Nesse contexto, como alerta Neuhouser, um ser que possui amor-próprio se impele à exigência de assumir a posição de ser levado em conta e de ser tomado como algo de valia. Este ser sente a necessidade, portanto, de ser observado e admirado, ou seja, de ser considerado como digno de valor (NEUHOUSER, 2009, p. 29).

A segunda oposição entre os dois tipos de sentimento humano consiste no fato de que enquanto o amor de si possui caráter absoluto, o amor-próprio é relativo. Neuhouser (2009) 
esclarece que relativo se refere aqui a outros sujeitos. Nesse sentido, o amor-próprio é relativo numa dupla perspectiva, da comparação e da dependência em relação à opinião dos outros.

No que diz respeito à primeira perspectiva, o bem que o amor-próprio aspira é de natureza comparativa no sentido de que querer ser considerado significa desejar uma determinada posição (colocação) que se relaciona diretamente com a posição de outros sujeitos. Ou seja, o respeito que o amor-próprio do sujeito quer conquistar é um bem posicional (positional good). Ter resultado - adquirir prestígio social como aspiração do sujeito - significa, para tal sujeito, ter resultado sempre em comparação com outros sujeitos. A extensão ou amplitude em que a necessidade por reconhecimento de um sujeito determinado é satisfeita depende, por conseguinte, do modo exitoso ou não com o qual outros também conseguem alcançar seu reconhecimento. Ora, algo diferente ocorre com o amor de si, que de modo algum é relativo, e, por isso, o bem que ele aspira não depende, em certo sentido, do quanto os outros sujeitos possuem ou não este bem. Por exemplo, o modo como a alimentação e o sono satisfazem suas necessidades físicas possui certo grau de independência em relação ao modo como outros sujeitos satisfazem suas próprias necessidades. Já no que diz respeito ao amor-próprio, a satisfação de suas necessidades depende da relação imediata entre quantidade e qualidade da estima que os outros dirijam a ele e a qualidade e quantidade de estima que os outros possuem sobre si mesmos (NEUHOUSER, 2009, p. 29). Em sintese, esta primeira perspectiva, na qual o amor-próprio é relativo, nos permite formular a tese de que o maior bem por ele aspirado consiste em ser reconhecido (estimado) pelo outro.

A segunda perspectiva aponta para o fato de que a aspiração do sujeito de ser estimado depende diretamente da opinião de outros sujeitos. 0 amor-próprio é relativo, neste segundo sentido, porque seu objetivo de ser reconhecido pelo outro é de natureza essencialmente social. Nesse contexto, ele não é somente relativo, senão também artificial. Com isso Rousseau não quer dizer, segundo Neuhouser (2009), que a aspiração por reconhecimento seja uma parte acidental da ação humana ou que sem o amor-próprio o homem seria melhor. Ao contrário disso, ele considera o amor-próprio como um fenômeno social de primeira grandeza, pois suas formas são diversificadas e dependentes da propriedade do mundo social inerentes aos seus portadores.

Neuhouser (2009) tem em mente aqui o fato, decisivo para a sociabilidade humana, de que os homens não podem existir sem o amor-próprio e o modo como tal sentimento se manifesta no mundo depende das instituições sociais a partir das quais ele é formado. Para se apreender este aspecto constitutivo do amor-próprio, é preciso considerá-lo, no entanto, como algo que não é fixo e imutável, mas sim plástico e fluido. Nesse sentido, como acentua o referido autor, o amor-próprio possui uma capacidade de metamorfose. Reconhecer isso é fundamental porque, do contrário, lhe seria atribuído somente uma conotação negativa, ficando-se impedido de buscar nele mesmo o antídoto contra a maldade que dele próprio se origina. Isto é, considerar a capacidade de mudança inerente ao amor-próprio significa igualmente considerar que se ele é a fonte principal do mal, de outra parte, não está determinado absoluta e irreversivelmente para o mal.

Além disso, como argumenta Neuhouser (2009), esclarecer o fundamento da mutabilidade do amor-próprio é importante porque a ele se liga seu caráter artificial. 0 amor-próprio prefere aceitar formas altamente variadas, porque a inclinação do sujeito para o prestígio social é conduzido em grande medida por suas opiniões, ou seja, pela representação que ele faz de si mesmo. Nesse contexto, a representação que o homem faz de si mesmo e o lugar que toma em relação à humanidade é decisivo para saber se a paixão do amor-próprio é humana ou prejudicial, boa ou má (NEUHOUSER, 2009, p. 30).

Em síntese, das duas oposições do amor-próprio em relação ao amor de si, Neuhouser (2009) extrai a tese de que o amor-próprio 
consiste na aspiração humana por reconhecimento e, na verdade, em um duplo sentido: primeiro, porque representa a necessidade inerente à ação humana de se comparar com os outros e, segundo, porque depende permanentemente da opinião e da estima do outro.

Mas em que sentido o amor-próprio é fonte do mal humano? Neuhouser (2009, p. 3334) elenca e justifica seis aspectos (problemas) que o tornam perigoso, transformando-o em fonte da maldade humana:

a) Por ser fonte da aspiração humana por reputação, honra e distinção, o amor-próprio põe os homens em permanente disputa e concorrência entre si, tornando-os inimigos declarados uns dos outros. Isso ajuda a esclarecer então, por um lado, por que a necessidade de autoconservação traduzida em aspiração por reconhecimento social constitui e dinamiza a sociabilidade humana e, por outro, por que tal sociabilidade é formada por um grau elevado de conflitos entre seus membros. Segundo Neuhouser (2009):

Não é em primeira linha a necessidade natural, mas sim a necessidade insatisfeita por reconhecimento (Anerkennung) que é responsável, segundo Rousseau, pelo relacionamento belicoso entre os indivíduos. (p. 33) ${ }^{4}$

b) Por aspirar uma posição social que sempre é determinada em relação à posição de outros sujeitos, a dinâmica interna do amor-próprio conduz inevitavelmente a um conflito insolúvel. Para Neuhouser (2009), a propriedade do amor-próprio torna-se perigosa, nesse sentido, porque o homem inclina-se rapidamente a substituir o "bem" pelo "melhor" em sua comparação com os outros, reduzindo, com isso, a busca por reconhecimento à busca por querer

4. Sob este aspecto, o conceito de amor-próprio auxilia na demarcação da enorme diferença entre os pensamentos de Rousseau e Hobbes no que diz respeito ao conceito de estado de natureza, indicando que o estado de guerra de todos contra todos é próprio do homem civil e de modo algum do homem natural. Sobre a diferença entre estes dois pensadores, ver Herb (1989). ser incondicionalmente melhor do que os outros. Salta aos olhos, então, o enorme problema que esta perspectiva perigosa cria:

Uma dificuldade evidente que traz consigo uma aspiração por posição superior (überlegener Stellung), ampliada universalmente, é tornar impossível a satisfação sistemática do amor próprio. (NEUHOUSER, 2009, p. 33)

Isso signifıca dizer que se todos aspiram simultaneamente por uma posição superior, é evidente que nem todos podem alcançá-la, pois o "superior" só adquire sentido em relação a uma posição inferior. Orientado por esta lógica, o reconhecimento social deixa de ser obra possível de ser alcançada por todos!

c) Por conter em si a aspiração por posição superior em relação aos demais, o amor-próprio torna-se fonte da luta concorrencial entre sujeitos. 0 problema consiste aí em que a superioridade conquistada, por estar em permanente dependência do reconhecimento dos outros, os quais também aspiram por superioridade, nunca pode ser uma superioridade absoluta e, por não sê-la, transforma-se em fonte de insegurança.

Problemático torna-se aí não somente o fato de o amor próprio encontrar satisfação insegura e fugitiva, senão também que as necessidades e os desejos se tornam a tal ponto ilimitados que danificam a felicidade humana. (NEUHOUSER, 2009, p. 34)

d) 0 amor-próprio também é problemático porque possui a tendência de produzir vícios ou comportamentos amorais. Vício significa, neste contexto, desprezar o sofrimento do outro, ou sentir-se feliz pela sua infelicidade. Dito de outro modo, por causa da predominância da aspiração por posição superior, os homens tornam-se completamente insensíveis em relação à condição e ao sofrimento dos outros: cada um torna-se inimigo do outro, e o que menos conta é o sentimento de pertença à mesma espécie. Segundo Neuhouser (2009), esta "propensão 
para o vício" (Hang zum Laster) significa, no contexto argumentativo de Rousseau, a opressão do sentimento natural de piedade, opressão à qual se expõe cada vez mais o homem civilizado (p. 34).

e) Porque a estima conquistada mediante o olhar do outro é uma parte do bem que o amor-próprio aspira, isso o coloca na dependência estrita do olhar do outro. Nesse sentido, a opinião positiva do outro é constitutiva do bem que ele aspira. 0 perigo que está inerente a este aspecto do amor-próprio se torna compreensível à luz do que Rousseau denomina de perigos da dependência em geral, os quais põem em risco a liberdade humana. A dependência está, neste contexto, em oposição à autonomia: o sujeito encontra-se em estado de dependência para satisfazer suas necessidades, pois precisa da cooperação de outros indivíduos. Afırma Neuhouser (2009):

0 pensamento político e social de Rousseau fundamenta-se na idéia de que cada modo de dependência traz consigo o perigo de que os indivíduos podem prejudicar sua liberdade ao satisfazer suas necessidades e isto ocorre porque precisam estar em cooperação com os outros. (p. 34)

Em síntese, o que Rousseau tem em mente aqui é o fato de que, se a estima pessoal depender muito do olhar do outro, tal dependência pode conduzir à perda da liberdade, pois submete excessivamente o sujeito à vontade de outros, impedindo-o de obedecer à sua própria vontade ${ }^{5}$.

f) Por fim, há ainda outro perigo que surge do fato de que o amor-próprio aspira um bem que depende do julgamento do outro. Este perigo se deixa descrever melhor pelo conceito

5. De outra parte, numa conhecida passagem das Lettres écrites de la montagne, Rousseau defende a liberdade não tanto com o fazer sua própria vontade, mas sim como não submeter a vontade de outro à nossa própria vontade. Ele está preocupado aqui com a relação entre liberdade e lei e quer garantir a ideia, central para seu pensamento político, de que ninguém deve estar acima da lei, inclusive o senhor: "Qualquer um que seja senhor não pode ser livre, pois dominar (reinar) é obedecer" (OC III 841). de alienação ou autoalienação, o qual está vinculado àquilo que Rousseau denomina de "existir fora de si" ou "sair fora de si" em que sentido o "sair fora de si" significa um estranhamento? No sentido de que o sujeito só consegue obter o sentimento de sua própria existência por meio do julgamento dos outros. Neste ponto, Rousseau formula, segundo Neuhouser (2009), uma tese central à sua filosofia social, a saber, de que a formação da identidade, isto é, a construção do self, depende do olhar do outro (p. 36). Isso significa dizer que a fonte da existência do sujeito - como identidade de um self (de um si mesmo) - não reside de modo algum só no sujeito, mas também no outro e, com isso, o próprio ser do sujeito repousa nas opiniões incertas e contingentes de seus semelhantes. Nesse sentido, buscar a estima pública tendo de se expor ao olhar público significa, simultaneamente, se expor às contingências e incertezas deste olhar. Quando este olhar impede a autoafırmação e o autodomínio pessoal, então o fenômeno do sair fora de si se torna destrutivo e, nesse sentido, a alienação se torna fonte do mal.

Este resumo nos oferece boas razões para considerar o amor-próprio como fonte do mal humano. Tais razões servem para esclarecer o quanto ele, tomado nesta sua dimensão negativa, pode se tornar altamente destrutivo às relações humanas e sociais. No entanto, se o amor-próprio não é, de acordo com a interpretação de Neuhouser, somente fonte do mal e, por isso, não é somente destrutivo, de onde provém a possibilidade de que seja também construtivo? Tratarei desta questão passando ao último tópico do ensaio, pois seu aspecto construtivo depende que se leve em consideração a educabilidade do amor-próprio.

6. Embora Neuhouser reconheça o fato de que Rousseau não empregou expressamente 0 conceito de alienação, afirma que tal conceito se encontra formulado nas entrelinhas de seu pensamento. Para legitimar sua interpretação, recorre ao estudo de Jaeggi, publicado recentemente (2005). 


\section{Do aspecto construtivo do amor-próprio e da necessidade de sua educação}

Da interpretação de Neuhouser (2009) fica assegurado, em linhas gerais, que o amor-próprio é constituído pela aspiração humana por reconhecimento, assumindo uma dimensão significativamente destrutiva na medida em que se consolida como busca obsessiva por posição superior. Considerando isso, duas alternativas seriam aparentemente as mais prováveis: a primeira, mais radical, concentra-se somente na dimensão destrutiva do amor-próprio, objetivando sua aniquilação; a segunda, talvez mais ingênua, propõe a sua educação por meio do retorno do amor de si e do sentimento de piedade a ele associado. Para Neuhouser (2009), estas duas alternativas não encontrariam respaldo maior no pensamento de Rousseau, pois o genebrino jamais pensou na possibilidade de eliminar o amor-próprio simplesmente porque o considerava como constitutivo do ser humano e de sua sociabilidade. Nesse sentido, querer eliminá-lo significaria o mesmo que querer pensar o homem sem suas paixões e sem sua racionalidade e, em síntese, sem sua própria subjetividade. De outra parte, a educação do amor-próprio por meio da piedade natural não seria possível porque a piedade, por si só, sem o auxílio da razão, seria cega, não conseguindo enfrentar sozinha, de modo satisfatório, o sentimento raivoso e odiento provindo do amor-próprio. Se o amor-próprio não pode ser eliminado das relações sociais, como também não possui só uma tendência destrutiva irreversível e, por último, não pode ser simplesmente corrigido pela piedade natural, então sua educabilidade deve ser buscada em outro lugar e ser pensada de outra forma.

Para fugir do aparente dilema de que se, por um lado, não podemos viver sem o amor-próprio e, por outro, ao deixar-nos orientar por ele, podemos ser levados à nossa própria destruição, Neuhouser (2009) acentua uma perspectiva imanente à posição de Rousseau, a qual transforma o amor-próprio numa condição necessária, mas não absoluta do mal humano. Tal perspectiva baseia-se em dois aspectos bem definidos: a) na capacidade de mudança e transformação inerente ao amor-próprio; b) no fato de que o amor-próprio não se caracteriza sempre, nem absoluta e nem definitivamente, pela aspiração em alcançar uma posição superior.

Como estes dois aspectos são decisivos para mostrar o caráter ambíguo do amor-próprio e, portanto, também o aspecto construtivo que lhe é inerente, precisamos compreendê-los mais de perto. Justamente neste ponto é que a interpretação de Neuhouser (2009), se mostra deficitária e, por isso, precisa ser complementada. É verdade que, ao justificar as razões que tornam o amor-próprio fonte do mal humano, o autor é cauteloso o suficiente para assegurar-lhe dinamicidade, atribuir-lhe, com isso, também a capacidade de transformação. Mas de onde provém tal capacidade do amor-próprio? A meu ver, Neuhouser não oferece uma resposta satisfatória para esta pergunta e não pôde fazê-lo porque não deu atenção devida para a centralidade que o conceito de perfectibilidade desempenha na investigação empreendida por Rousseau para esclarecer os fundamentos da sociabilidade humana.

Como vimos, Rousseau mostra, já no Segundo discurso, que a sociabilidade humana não teria sido possível sem a dupla condição humana, de ser um agente livre e de ser capaz de se aperfeiçoar. $\mathrm{Na}$ meditação sobre o percurso desenvolvido pelo homem, desde o instante em que ele "saiu das mãos da natureza”, Rousseau concebe a liberdade e a perfectibilidade como condição da aspiração humana por reconhecimento, a qual é levada adiante pelo amor-próprio. Nesse sentido, é a perfectibilidade, enquanto "faculdade das faculdades", que assegura à natureza humana sua plasticidade e indeterminabilidade ${ }^{7}$. Ora, para o ponto

7. Ocupei-me amplamente com o conceito de perfectibilidade no pensamento de Rousseau na conferência intitulada "Perfectibilité e formação 
que nos interessa, são estas duas características que, em última instância, garantem ao amor-próprio sua capacidade de transformação e, portanto, que podem impedi-lo de assumir somente uma direção destrutiva. Em síntese, porque o homem é um ser perfectível, no sentido de ser indeterminado, mas apto a se construir, é que também fica aberta ao amor-próprio uma possibilidade construtiva.

Penso que esta complementação à interpretação de Neuhouser torna sua própria posição mais clara e consequente. Com base nisso, podemos analisar agora em que consiste e onde reside essa dimensão construtiva. Para Neuhouser (2009), ela deriva, em última instância, do fato de o amor-próprio ser o protótipo da razão. Mas em que consiste isso? Para justificá-la, ele recorre à filosofia social de Georg Herbert Mead, de modo especial à sua teoria do assumir a perspectiva do outro como condição da sociabilidade racional humana. Eu só posso me reportar aqui ao essencial da reconstrução de Neuhouser, sem ter condições de me ater aos detalhes e nem refletir sobre as possíveis dificuldades e limites que são inerentes tanto à filosofia social de $\mathrm{Mead}^{8}$ como à tentativa de interpretar o pensamento de Rousseau à luz de tal filosofia.

Com base nisso, Neuhouser (2009) assume a tese de que o aspecto construtivo do amor-próprio brota da própria capacidade humana originária de sair fora de si e de se comparar com os outros. Esta capacidade conduz à razão e esta, por sua vez, abre ao homem a possibilidade de fazer uso normativo de seu sentimento do amor-próprio. Em síntese, a tese de fundo é que Rousseau atribui uma base normativa clara à sua filosofia do reconhecimento social, a qual repousa na dimensão construtiva do amor-próprio. As pressuposições aqui são muitas, assim como as necessidades de seu esclarecimento.

humana no pensamento de Jean-Jacques Rousseau", proferida no IV Colóquio Rousseau, ocorrido na UEL/PR, em novembro de 2008. Sobre isso, ver Dalbosco (2010).

8. Sobre isso, ver meu recente livro (DALBOSC0, 2010b, p. 27-48; p. 213-243).
Para que a razão possa assumir o papel de ordenadora da ação humana, assim reza o argumento, os seres isolados do estado selvagem devem abandonar esta sua condição e aprender a agir segundo princípios mediante os quais a perspectiva de seus semelhantes deve ser tomada em consideração. Nesse sentido, o genebrino vê no amor-próprio, com seu interesse explícito no ponto de vista do outro, o recurso indispensável da natureza humana que a conduz a romper com a perspectiva inicial centrada em si mesma. 0 núcleo reside aqui, como se vê, no argumento de que o amor-próprio só pode se constituir como fonte primeira da sociabilidade humana porque traz consigo a capacidade de assumir a perspectiva do outro. Mais ainda, porque ele aspira pela boa opinião do outro - pois seria um absurdo que alguém em condições normais desejasse que lhe fizessem o mal -, sua satisfação depende, nesse sentido, da capacidade de antecipar os desejos e as necessidades dos outros e produzir ações em comum acordo com elas (NEUHOUSER, 2009, p. 46).

0 saldo positivo disso é que o sentimento do amor-próprio nos pressiona permanentemente para aperfeiçoar nossa capacidade de ver o mundo de outro ponto de vista além do nosso. Nesse sentido, não há duvida de que ele contribui para a formação da razão na medida em que estimula os indivíduos ao desenvolvimento de sua capacidade de se autorrepresentar, tendo também que compreender como os outros percebem seu próprio mundo e o mundo de seus parceiros (concorrentes).

Tal dinâmica é garantida, segundo Neuhouser (2009, p. 47-48), pelo aspecto específico que constitui o amor-próprio, ou seja, por aqueles dois aspectos, já vistos acima, que o tornam uma paixão humana relativa: a) pelo fato de que a posição aspirada por ele é sempre uma posição em relação ao outro; b) e porque o bem por ele aspirado - que é o bem baseado no respeito social (soziale Achtung) - depende sempre da opinião de outros sujeitos e só pode manifestar-se por intermédio dessa 
opinião. Como esses dois aspectos transformam o amor-próprio num sentimento cada vez mais racional, eles auxiliam também para mostrar a insuficiência da piedade natural como fundamento da ação racional. Significando a capacidade de sentir o sofrimento do outro, a piedade deve ser conduzida pela razão para evitar tornar-se cega. Pelo fato de os indivíduos humanos possuírem valor $\mathrm{e}$ adquirem estima pública somente em comparação com os outros, daí advém um aspecto racional para a ação humana que possibilita ao amor-próprio ser fonte de regulação da piedade natural.

Se o amor-próprio deve trazer uma contribuição decisiva para a ação racional, o reconhecimento da subjetividade do outro não pode consistir somente na antecipação de suas alegrias e sofrimentos. Nesse sentido, o amor-próprio diferencia-se do amor de si porque ele nos ensina a nos interessar não somente pela perspectiva que o outro possui sobre um assunto em geral, mas sobre sua perspectiva em relação a um objeto determinado, a saber, sobre nós mesmos. Isso significa dizer que, se alguém quer fazer com que o outro tenha uma boa opinião sobre si, deve procurar se apresentar com aspectos determinados de si mesmo que possam influenciar os sujeitos que se encontram em outra situação, fazendo com que o sujeito perceba sua representação pública de tal forma que possa avaliá-la positivamente (NEUHOUSER, 2009, p. 48).

Em síntese, o amor-próprio torna-se construtivo porque impele a ação humana a racionalizar-se progressivamente, provocando no sujeito sua descentração numa dupla perspectiva, como exigência de levar em consideração a perspectiva do outro e, ao fazer isso, de pensar sobre si mesmo. Como afirma Neuhouser (2009):

Com seu interesse consistindo no modo como é visto por outros sujeitos, parece ser o amor próprio particularmente capaz de exigir de cada ser humano aquela capacidade de auto-objetivação que é a pressuposição de sua auto-avaliação racional (vernünftige Selbsteinschätzung). (p. 49)

Nesse sentido, o amor-próprio torna-se construtivo porque, ao possibilitar a consideração da perspectiva do outro, conduz o sujeito a refletir sobre si mesmo tomando como parâmetro um ponto de vista externo.

Se com isso fica estabelecido o aspecto construtivo do amor-próprio, como se vincula a ele a necessidade de educação? A resposta mais imediata consiste em afırmar que, se a exigência de levar em consideração a perspectiva do outro é constitutiva da sociabilidade humana e isto porque contém em germe a possibilidade da autorreflexão, à qual se ligam tanto a liberdade como a moralidade humana, o fato é que ninguém já nasce com a capacidade inteiramente pronta de se colocar no lugar do outro e muito menos de se colocar eticamente (normativamente) no lugar do outro. Portanto, tal capacidade precisa ser educada.

Não há dúvida de que Rousseau empreendeu, posteriormente ao Segundo discurso, sobretudo no Emílio, esforços detalhados no sentido de mostrar a importância da educabilidade do amor-próprio e das dificuldades inerentes a tal tarefa. 0 que se poderia compreender aí como aspectos de uma "educação prática" aparece no esboço de um projeto de educação natural e social desenvolvido ao longo dos cinco livros que compõem a referida obra ${ }^{9}$. Nesta dupla dimensão de um mesmo projeto, que visa a formação para a maioridade, destaca-se o modo singular com o qual o genebrino pensa a relação pedagógica entre educador e educando, indicando os limites e os desafios de tal relação. No âmbito da educação natural, por exemplo, trata-se de proteger ao máximo a criança da invasão viciosa do mundo adulto, colocando-a em contato permanente com a

9. Coordenei um projeto de investigação, durante os anos de 2008 e 2009, que teve como fio condutor o papel do educador como governante no Emílio de Rousseau. Os resultados de tal investigação sairão em breve numa coletânea (DALBOSCO, 2011). 
natureza, visando o fortalecimento de seu corpo e o refınamento de seus sentidos. É nesse sentido que a educação natural é concebida como educação negativa. No âmbito da educação social (moral), por sua vez, quando o educando já teria atingido uma idade razoável, trata-se de acompanhá-lo em seu ingresso definitivo e soberano na sociedade adulta. Ora, tanto na educação natural como social destaca-se o papel do educador como governante que, para poder executar adequadamente sua tarefa, precisa saber, antes de tudo, governar a si mesmo, e isso significa dizer que ele precisa aprender a dominar suas paixões odientas e irascíveis.

\section{Referências}

BUCK, Günter. Selbsterhaltung und Historizität. In: EBELING, Hans. Subjektivität und Selbsterhaltung: Beiträge zur Diagnose der Moderne. Frankfurt am Main: Suhrkamp, 1996, p. 97-121.

DALBOSCO, Claudio Almir. Crítica à cultura, sociabilidade moral e amour de l'ordre em Rousseau. In: Contexto \& Educação, ano XXIV, n. 82, 2009, p. 13-33.

Perfectibilité e formação humana no pensamento de Jean-Jacques Rousseau. Passo Fundo, 2010a. (Ensaio inédito)

Pragmatismo, teoria crítica e educação: ação pedagógica como mediação de significados. Campinas: Autores Associados, 2010b.

(Org.). Filosofia e educação no Emílio de Rousseau: o educador como governante. Campinas: Átomo \& Alínea, 2011.

HENRICH, Dieter. Die Grundstruktur der modernen Philosophie. In: EBELING, Hans. Subjektivität und Selbsterhaltung: Beiträge zur Diagnose der Moderne. Frankfurt am Main: Suhrkamp, 1996, p. 97-121.

HERB, Karlfriedrich. Rousseaus Theorie legitimer Herrschaft: Voraussetzungen und Begründungen. Würzburg: Königshausen \& Neumann, 1989.

JAEGGI, Rahel. Entfremdung. Frankfurt am Main: Suhrkamp, 2005.

NEUHOUSER, Frederic. Rousseau's theodicy of 'amour propre': evil, rationality and the drive for recognition. Oxford, 2008.

. Rousseau und das menschliche Verlangen nach Anerkennung. In: BUSCH, Hans-Christoph Schmidt am; ZURN, Christopher F. (Hrsg.). Anerkennung. Berlin: Akademie Verlag, 2009, p. 27-51. (Deutsche Zeitschrift für Philosophie, Sonderband 21).

ROUSSEAU, Jean-Jacques. Oeuvres complètes. Paris: Gallimard, tomo III, 2003. (Bibliothèque de la Plêiade.)

Discurso sobre a origem e os fundamentos da desigualdade entre os homens. Tradução de Lourdes Santos Machado. São Paulo: Abril Cultural, 1978. (Os Pensadores.)

Recebido em: 04.08.2010

Aprovado em: 11.12.2010

Claudio Almir Dalbosco é professor do curso de Filosofia e do Programa de Pós-graduação em Educação da Universidade de Passo Fundo (RS). 